\title{
Entrepreneurship and regional economic growth in Antioquia: An empirical analysis
}

\author{
Sebastian Aparicio ${ }^{1}$ - David Urbano ${ }^{2 *} \bullet$ Diego Gomez ${ }^{3}$ \\ ${ }^{1}$ Durham University Business School, Durham University, Durham, UK \\ ${ }^{2}$ Department of Business, Universitat Autonoma de Barcelona, Barcelona, Spain \\ ${ }^{3}$ Fundación ECSIM, Medellín-Colombia
}

Received: 2 April 2018

Revised: 3 July 2018

Accepted: 3 July 2018

\begin{abstract}
Drawing on the concept of entrepreneurship capital, which links collective entrepreneurial action with growth, this paper aims to explore the effect that entrepreneurship has had on the economic growth of Antioquia (Colombia). We estimate a growth model using unbalanced panel data with fixed effects for the period 2001-2012. In this study, entrepreneurship is measured as the number of new businesses and the ratio of new and discontinued companies, which have a positive impact on the economic growth of Antioquia. These results motivate a discussion about the importance of public policy in creating an environment that stimulates entrepreneurship and productive expansion; this should be maintained over time under the same social and economic purposes.
\end{abstract}

Keywords: economic growth; entrepreneurship; local development; Antioquia; Colombia JEL Classification Codes: O4, L26, R58

\section{Introduction}

Past studies have comprehensively demonstrated that entrepreneurial activity and economic development are recursively linked (Amorós et al., 2017); scholars agree that the creation of new ventures and small businesses not only affect economic activity at both country level (Bosma et al., 2018; Urbano \& Aparicio, 2016) and regional level (Audretsch \& Keilbach, 2004, 2008), but affect social outcomes as well (McMullen, 2011). When certain institutions exist and operate properly, entrepreneurship may be more beneficial for growth and development in certain situations (Bjørnskov \& Foss, 2016). According to Aparicio et al. (2016a), both formal and informal institutions must be aligned in order to create a supportive environment for those who want to become entrepreneurs. In this regard, scholars have identified that both regions and

\footnotetext{
*Corresponding author. E-mail: david.urbano@uab.cat

Citation: Aparicio, S., Urbano, D., and Gomez, D. (2018) Entrepreneurship and regional economic growth in Antioquia: An empirical analysis, Economics and Business Letters, 7(2), 84-91.
} 
countries differ in their quantity and quality of entrepreneurial activity (Acs et al., 2008; Fritsch \& Mueller, 2004). Despite these findings, Naudé (2010) and Urbano et al. (2018) have claimed that further works should be conducted, particularly because there is a scarcity of evidence considering regional studies in developing countries.

Colombia and its regions could constitute an interesting laboratory in which to test the hypothesis that entrepreneurship is key for economic growth and development. In this sense, Aparicio et al. (2016b) showed that innovation and entrepreneurship could represent key elements that foster economic activity in the medium- and long-term. Coscia et al. (2017) demonstrated that despite the problems existing in Colombia, some regions present a faster convergence process than others. Within these regions, Antioquia has been highlighted as a highly dynamic state due to its solid industrial and business history. Aparicio et al. (2016b) pointed out that despite issues with violence in the region, Antioquia is characterized by its entrepreneurial culture. The state of Antioquia and its capital city, Medellin, went through a long period of stagnation in the second half of the twentieth century, with a persistent phenomenon of unemployment, as well as an emerging organized crime industry, which in turn generated various stages of violence and social problems, such as poverty and inequality. Different strategies from public and private actors successfully led to the reemergence of Antioquia as a highly productive region in which social problems could be solved using entrepreneurship as an enduring societal characteristic (e.g. Centros de Desarrollo Empresarial Zonal -Cedezos; Parque E; Cultura E, Innpulsa, etc.). Despite these endeavors, there is still limited evidence proving whether entrepreneurship has contributed to the Antioquia's economic growth.

Thus, this paper seeks to explore the effect that entrepreneurship has had on the economic growth of Antioquia (Colombia). To this end, we draw on the concept of entrepreneurship capital developed by Audretsch and Keilbach (2004). To empirically assess this relationship, data on both new firms and dissolved companies will be used, in addition to local reports from the National Administrative Department of Statistics (DANE) and the Chamber of Commerce of Medellin for Antioquia. The latter is the organization in charge of business registration in the city of Medellin and some sub-regions of Antioquia. The period of analysis is from 2001 to 2012. Additional information on GDP, capital investment and employment rates in Medellin and its metropolitan area are also taken from DANE. For the quantitative exercise, an unbalanced panel data model analyzing sectorial productivity is performed. A sample of 108 observations (nine economic sectors over 12 years) is used to test our hypothesis.

This paper develops according to the following structure. In addition to the introduction, Section 2 discusses the extant literature on the importance of entrepreneurship for growth, where the concept of entrepreneurship capital is analyzed. Section 3 presents the model and data we use to test our hypothesis. Section 4 describes the estimation results. Finally, Section 5 discusses the study's implications and conclusions, and offers future research possibilities.

\section{Conceptual framework}

From a theoretical perspective, the analysis of economic growth in regions and countries has changed in recent years (Solow, 2007). From the neoclassical foundations of Solow (1956) and Swan (1956), developments by Lucas (1988), Romer (1986) and Aghion and Howitt (1992) led to a new family of models known as endogenous growth models. Solow (2007) highlights the evolution that these sorts of models has had across time. He recognizes that the mathematical foundation of Solow-Swan specification enables the inclusion and assessment of different variables (e.g. human capital, institutions, specializations in commodities and terms of trade) that may also explain growth. In this regard, other variables that have been put aside by the traditional growth theory are emerging as important factors that spur economic growth (Solow, 2007). 
On the Solow-Swan bases, Audretsch and Keilbach (2004) introduced the concept of entrepreneurship capital, which assumes a direct connection between entrepreneurial activity and economic growth. According to these authors, entrepreneurship capital is determined by a number of regional factors which are critical in the creation of new businesses. These factors deal with the provision of innovative individuals, social acceptance of entrepreneurial activity, government strategies that promote entrepreneurship and an ecosystem that enables the support of processes and idea implementation through training and financial resources. Therefore, it is likely that regions endowed with these characteristics have more entrepreneurship capital and, hence, higher levels of economic growth. Drawing on these ideas, Audretsch and Keilbach (2008) have modeled the impact of entrepreneurship capital on regional growth in Germany by considering the underlying influence of the context. According to these authors, entrepreneurship capital reflects the institutional environment that leads to higher levels of growth and development, as explained in its definition.

The above perspective has largely been explored in developed countries (Audretsch \& Fritsch, 2002; Audretsch \& Keilbach, 2004; Berkovitz \& Dejong, 2005; Mueller, 2007; Noseleit, 2012; Stephens \& Partridge, 2011). Although previous studies show a positive relationship between entrepreneurship and economic growth, two previously ignored aspects encourage further work on the subject; first, relationships in developing countries may or may not have the same magnitude as relationships in developed countries. Secondly, based on the entrepreneurship capital approach, it is not only possible to understand the relationship between two variables, but the interactions generated within the environment that leads to some regions being more developed than others (Aparicio et al., 2016a; Bosma et al., 2018).

In the specific case of Antioquia, Hurtado et al. (2010) and Gómez et al. (2015) assessed how the creation of new businesses could be related to long-term economic growth. Similar to the extant literature, these authors concluded that there is a positive marginal relationship between these two variables. In this case, one might think that, overall, entrepreneurship may have an effect on Antioquian economic growth. Consequently, further evidence may serve to test whether there is a positive correlation between entrepreneurship and the economic performance of Antioquia. The next section describes the methodology used to test this idea.

\section{Methods}

Audretsch and Keilbach $(2004,2008)$ suggest that entrepreneurship should not only be understood as a mere factor of production but as a variable embracing social capital and innovation processes. Following the conceptual approach of entrepreneurship capital, this section estimates an economic growth model for Antioquia. The starting point is the model presented by Solow (1956) and Swan (1956), which presents fundamental factors, such as capital and labor, to explain the differences in growth between countries. In this case, Audretsch and Keilbach (2004) introduced the variable of entrepreneurship capital in the production function:

$$
Y_{i t}=\alpha K_{i t}^{\beta_{1}} L_{i t}^{\beta_{2}} E_{i t}^{\beta_{3}}
$$

where $Y_{i t}$ represents the total production (the Antioquia GDP in constant terms; 2005 is the baseline), $\alpha$ (the intercept of the model) is productivity, the stock of capital is $K_{i t}$ (the capital invested by companies, which is also in constant terms), $L_{i t}$ serves to approach employment rates (which is the number of employees in Medellin and its metropolitan areas) and $E_{i t}$ is the level of entrepreneurship in the sector $i$ of Antioquia (which is the total number of new registered firms, as well as the ratio between new and discontinued companies). It is worth noting that most of the variables are measured at the state level, but since Medellin represents about 75\% of Antioquia's employment (Aparicio et al., 2013; Hurtado et al., 2010), we have assumed $L_{i t}$ as a properly proxy in our model. For the purposes of this research, the above function is 
linearly estimated using panel data with fixed effects. Against random effects, this technique allows for an accurate analysis given the sample size limitations (e.g. omitted variables) (Cameron $\&$ Trivedi, 2005). Thus, we have used natural logarithms to linearize the production function, which affords us a direct interpretation of the estimated coefficient as the percentage change of economic growth when each explanatory variable varies by $1 \%$ (Wooldridge, 2012). Therefore, equation 2 is as follows:

$$
\operatorname{Ln} Y_{i t}=\operatorname{Ln} \alpha+\beta_{1} \operatorname{Ln} K_{i t}+\beta_{2} \operatorname{Ln} L_{i t}+\beta_{3} \operatorname{Ln} E_{i t}+d_{i}+\varepsilon_{i t}
$$

The information used to estimate equation 2 corresponds to nine productive sectors $\left(d_{i}, i=1\right.$, $\ldots, 9$ ) in the years $(t)$ 2001-2012: agriculture; mines and oil; manufacturing; electricity, gas and water; construction; commerce, restaurants and hotels; transport and communication; insurance and finance; social and personal services. $\varepsilon_{i t}$ is the error term that captures other variables influencing the economic growth of Antioquia. The panel used is unbalanced in the years in which the value of zero or missing for the dissolved companies is reported, thus avoiding indeterminate results in the ratio of new and dissolved companies, which is one of the variables evaluated in the model. By doing this, we also clean up possible biases and issues that come with the data set as it is not possible to track why some sectors do not have dissolved firms (or information) for certain years. Feasible Generalized Least Squares (FGLS) were used; this allowed us to overcome biases related to heteroskedasticity and autocorrelation problems. Thus, reliable estimates are obtained and a dynamic model is implicitly estimated by taking into account the dependent variable, which is lagged by one period. The delay allows the disturbances to have different variances for each panel and are constant within panel. By assuming this, FGLS is asymptotically efficient and produces maximum likelihood estimates of the parameters.

\section{Results}

Table 1 shows the descriptive statistics and correlation matrix. According to these results, the correlation between the variables met our expectations. This might imply that firm dynamics (new and discontinued companies) follow the GDP cycle.

Table 1. Descriptive statistics and correlation matrix.

\begin{tabular}{|c|c|c|c|c|}
\hline Variable & Mean & Std. Dev. & Min & $\operatorname{Max}$ \\
\hline $1 G D P$ & $5.3 \mathrm{E}+12$ & $3.1 \mathrm{E}+12$ & $7.3 \mathrm{E}+11$ & $1.4 \mathrm{E}+13$ \\
\hline 2 Capital & $1.0 \mathrm{E}+08$ & $1.8 \mathrm{E}+08$ & 127349 & $9.6 \mathrm{E}+08$ \\
\hline 3 Employees & 166083.1 & 146749.4 & 399.3 & 499871 \\
\hline 4 New firms & 434.2 & 473.9 & 15 & 2257 \\
\hline 5 Discontinued firms & 112.3 & 116.5 & 1 & 422 \\
\hline Variable & 1 & 2 & 3 & 4 \\
\hline $1 G D P$ & 1 & & & \\
\hline 2 Capital & $0.795^{*}$ & 1 & & \\
\hline 3 Employees & $0.771 *$ & $0.867 *$ & 1 & \\
\hline 4 New firms & $0.336^{*}$ & $0.362 *$ & $0.222 *$ & 1 \\
\hline 5 Discontinued firms & $0.613^{*}$ & $0.576^{*}$ & $0.646^{*}$ & $0.003^{*}$ \\
\hline
\end{tabular}

$* \mathrm{p}<0.1$. Std. Dev. Standard deviation.

Table 2 presents the results of the two models of economic growth. The first model, in addition to the traditional variables of growth (capital and labor), contains the effect of new compa- 
nies incorporated; the second model estimates the ratio of new and discontinued firms. As mentioned before, we use (sector) fixed-effects to estimate our model. These parameters are not reported in Table 2 as the $x t g l s$ command in Stata 14 estimates them implicitly without losing degrees of freedom (Cameron \& Trivedi, 2005). Both models present a high Wald test $X^{2}(11)$ (1440.24 for Model 1, and 1381.21 for Model 2), which implies a good specification for both models.

Table 2. Estimating the Antioquian GDP.

\begin{tabular}{|c|c|c|c|c|}
\hline & \multicolumn{2}{|c|}{$\begin{array}{c}\text { (1) } \\
\text { Ln GDP Antioquia }\end{array}$} & \multicolumn{2}{|c|}{$\begin{array}{c}\text { (2) } \\
\text { Ln GDP Antioquia }\end{array}$} \\
\hline & $\beta$ & Std. Error & $\beta$ & Std. Error \\
\hline Ln Capital & $0.020 * * *$ & $(0.008)$ & $0.036 * * *$ & $(0.009)$ \\
\hline Ln Employees & $0.058^{*}$ & $(0.031)$ & $0.113^{* * *}$ & $(0.037)$ \\
\hline Ln New firms & $0.199 * * *$ & $(0.032)$ & & \\
\hline Ln New/discontinued firms ratio & & & $0.072 * * *$ & $(0.024)$ \\
\hline Constant & $27.051 * * *$ & $(0.314)$ & $27.091 * * *$ & $(0.369)$ \\
\hline Observations & \multicolumn{2}{|c|}{94} & \multicolumn{2}{|c|}{94} \\
\hline Fixed-effects & \multicolumn{2}{|c|}{ Yes } & \multicolumn{2}{|c|}{ Yes } \\
\hline Wald $X^{2}(11)$ & \multicolumn{2}{|c|}{1440.24} & \multicolumn{2}{|c|}{1381.21} \\
\hline
\end{tabular}

$* \mathrm{p}<0.1, * * \mathrm{p}<0.05 . * * * \mathrm{p}<0.01$. Robust standard errors in parentheses.

The first model considers entrepreneurship, the aforementioned first variable, and the traditional variables included in an economic growth production function, which were positive and significant. In terms of capital and labor, the results are consistent with those found in the seminal papers of Solow (1956) and Swan (1956), who suggested that part of economic growth can be explained by the ability to invest in machinery, equipment (capital) and labor. In terms of entrepreneurship, we find that the creation of new businesses positively and significantly influences the economic growth of Antioquia $(\mathrm{p}<0.01)$. The second model also considers the traditional variables; in this case, the ratio between new and dissolved firms was assessed. The results show that this variable also has a positive effect and is statistically significant $(\mathrm{p}<0.01)$ for Antioquian economic growth.

Both results support the hypothesis proposed in Section 2 on the possible correlation between entrepreneurship and the economic growth of Antioquia. In the case of Model 1, our evidence is in line with that of Audretsch and Keilbach $(2004,2008)$, who also found a positive relationship between entrepreneurship capital and regional economic growth in Germany; Audretsch and Keilbach (2004) used the number of new businesses per thousand inhabitants as the entrepreneurship capital value. What is interesting is that in our case, a simple variable that refers only to the number of newly created firms created similar results. While Audretsch and Keilbach (2004) estimate that entrepreneurship capital affects $0.17 \%$ of the economic growth of German regions, our results suggest that a $1 \%$ change in entrepreneurship levels can affect Antioquian economic growth by $0.19 \%$, ceteris paribus.

\section{Discussion and conclusions}

In this paper, an unbalanced panel data model with fixed effects was used to assess the effect that entrepreneurship had on the economic growth of Antioquia (Colombia) in the period from 2001 to 2012. Drawing on the entrepreneurship capital concept (Audretsch \& Keilbach, 2004, 2008), we were able to positively relate new business creation to Antioquian economic growth. 
The results obtained in both models enable us to discuss a series of implications for entrepreneurship, business expansion and economic growth at regional level. On the one hand, this paper presents evidence that entrepreneurship is relevant for the economic growth of Antioquia. The constant balance between the number of firms that pass through different stages (i.e. from inception to maturity to expansion) may require a specific business environment that allows them to exploit high potential. This means, as suggested by Model 2, that the Antioquian economy can grow either as a result of the number of new businesses growing faster than the amount of discontinued companies, or because the rate of discontinued firms was decelerating, or a combination of the two; there is high growth in the number of new businesses and a low rate of discontinued companies. Here it is important to clarify that our models have considered those firms belonging to the formal sector as the information only exists for these companies registered in the chamber of commerce. In this sense, the constant term in our estimated models might also suggest that other factors such as businesses in the unofficial economy (cf. De Castro et al., 2014) as well as larger firms competing in international markets (e.g. Gonzalez-Perez \& Velez-Ocampo, 2014) may contribute to the economic growth of Antioquia.

Despite the large informality, our findings may indicate that the government and private sector should keep working on initiatives that increase the base of individuals capable of identifying business opportunities. Aparicio et al. (2016a), Bosma et al. (2018) and Urbano et al. (2018) have suggested that different institutional factors (i.e. regulations, policies, culture, social norms, etc.) exert influence on entrepreneurial activity. Thereby, public and private actors should tend to create a favorable atmosphere for entrepreneurship, which should be durable and expandable over time. This does not imply that all projects must be innovative, but it does mean that programs of support and advice could guide both formal and informal entrepreneurs towards identifying niche markets, product differentiation, cost-effective supplies and/or organized management, among many other elements. Our findings could suggest that if these public and private initiatives exert the expected influence on entrepreneurship, then a higher regional growth can be accomplished.

Ács et al. (2014) suggested that Colombia was following the correct path in terms of entrepreneurship and supportive institutions. According to these authors, Colombia is ranked 23 out of 88 economies in the Global Entrepreneurship and Development Index (GEDI); this index basically shows that there is a balance between the level of entrepreneurship and economic development, grounded mainly on a national and regional system of entrepreneurship. This evidence for Colombia invites scholars to explore the underlying influence of institutions on entrepreneurship, which spurs at the same time economic growth. So far, our study is modestly concentrated on entrepreneurial activity as antecedent of regional growth, leaving room for future research that might be interested in tackling the causal chain that runs from institutions, entrepreneurship to economic growth (Bjørnskov \& Foss, 2016; Urbano et al., 2018), and convergence across regions (Le Gallo \& Delgado, 2013). Furthermore, since our data do not capture unofficial firms, future avenues can lead research towards new evidence that comprises the effect of both formal and informal entrepreneurship on the economic growth not only of Antioquia, but the rest of Colombia and Latin America.

\section{Acknowledgements}

The authors wish to thank Cámara de Comercio de Medellín para Antioquia for providing the data on new and discontinued firms. In addition, the authors acknowledge useful comments by Franciso Delgado, José Ernesto Amorós and two anonymous referees. Particularly, David Urbano acknowledges the financial support from projects ECO2017-87885-P (Spanish Ministry of Economy \& Competitiveness) and 2017-SGR-1056 (Economy \& Knowledge Department, Catalan Government). 


\section{References}

Ács, Z. J., Autio, E., and Szerb, L. (2014) National systems of entrepreneurship: Measurement issues and policy implications. Research Policy, 43(3), 476-494.

Acs, Z. J., Desai, S., and Klapper, L. F. (2008) What does "entrepreneurship" data really show?, Small Business Economics, 31(3), 265-281.

Aghion, P., and Howitt, P. (1992) A model of growth through creative destruction, Econometrica, 60(2), 323-351.

Amorós, J. E., Ciravegna, L., Mandakovic, V., and Stenholm, P. (2017) Necessity or opportunity? the effects of State fragility and economic development on entrepreneurial efforts, Entrepreneurship Theory and Practice, in press, doi: 10.1177/1042258717736857.

Aparicio, S., Ramírez Hassan, A., and Gómez Sánchez, D. F. (2013) Elección de ocupaciones que generen empleo usando modelos de elección discreta: Medellín Área Metropolitana 2009, Estudios Gerenciales, 29(129), 476-484.

Aparicio, S., Urbano, D. and Audretsch, D. (2016a) Institutional factors, opportunity entrepreneurship and economic growth: Panel data evidence. Technological Forecasting and Social Change, 102, 45-61.

Aparicio, S., Urbano, D., and Gómez, D. (2016b) The role of innovative entrepreneurship within Colombian business cycle scenarios: A system dynamics approach, Futures, 81, 130147.

Arshed, N., Carter, S., and Mason, C. (2014) The ineffectiveness of entrepreneurship policy: is policy formulation to blame?, Small Business Economics, 43(3), 639---659.

Audretsch, D. B., and Fritsch, M. (2002) Growth regimes over time and space, Regional Studies, 36(2), 113-124.

Audretsch, D. B., and Keilbach, M. (2004) Does entrepreneurship capital matter?, Entrepreneurship Theory and Practice, 28(5), 419-429.

Audretsch, D. B., and Keilbach, M. (2008) Resolving the knowledge paradox: Knowledgespillover entrepreneurship and economic growth, Research Policy, 37(10), 1697-1705.

Berkowitz, D., and DeJong, D. N. (2005) Entrepreneurship and Post-socialist Growth, Oxford Bulletin of Economics and Statistics, 67(1), 25-46.

Bjørnskov, C., and Foss, N. J. (2016) Institutions, entrepreneurship, and economic growth: what do we know and what do we still need to know?, The Academy of Management Perspectives, 30(3), 292-315.

Bosma, N., Sanders, M., and Stam, E. (2018) Institutions, entrepreneurship, and economic growth in Europe, Small Business Economics, in press, doi: 10.1007/s11187-018-0012-X.

Cameron, A. C., and Trivedi, P. K. (2005) Microeconometrics: Methods and applications, Cambridge: Cambridge University Prees.

Coscia, M., Cheston, T., and Hausmann, R. (2017) Institutions vs. Social Interactions in Driving Economic Convergence: Evidence from Colombia, CID Faculty Working Paper No. 331, Harvard University.

De Castro, J. O., Khavul, S., and Bruton, G. D. (2014) Shades of grey: how do informal firms navigate between macro and meso institutional environments?, Strategic Entrepreneurship Journal, 8(1), 75-94.

Fritsch, M., and Mueller, P. (2004) Effects of new business formation on regional development over time, Regional Studies, 38(8), 961-975.

Gonzalez-Perez, M. A., and Velez-Ocampo, J. F. (2014) Targeting one's own region: Internationalisation trends of Colombian multinational companies, European Business Review, 26(6), 531-551.

Gómez, D., Aparicio, S., and Urbano, D. (2015) Capital emprendedor y su influencia en el crecimiento económico de Antioquia. Gómez et al. (Eds.): Una apuesta por Medellín. Medellín: Fondo Editorial Corporación Univesitaria Remington, 17-43. 
Hurtado, Á., León Gómez, G., Támara Ayús, A. L., Buriticá Chica, M., and Pacheco, O. L. (2010) Empresarios, crecimiento económico, mercado de trabajo y capitales. Una visión empírica de Antioquia en el período 1994-2006, Revista Ciencias Estratégicas, 17(22), 197215.

Le Gallo, J., and Delgado, F. J. (2013). Introduction to the Special Issue on Revisiting Convergence, Economics and Business Letters, 2(4), 140-142.

Lucas Jr., R. E. (1988) On the mechanics of economic development, Journal of Monetary Economics, 22(1), 3-42.

McMullen, J. S. (2011) Delineating the domain of development entrepreneurship: a marketbased approach to facilitating inclusive economic growth, Entrepreneurship Theory and Practice, 35(1), 185-193.

Mueller, P. (2007) Exploiting Entrepreneurial Opportunities: The Impact of Entrepreneurship on Growth,. Small Business Economics, 28(4), 355-362.

Naudé, W. (2010) Entrepreneurship, developing countries, and development economics: new approaches and insights, Small Business Economics, 34(1), 1-12.

Noseleit, F. (2012) Entrepreneurship, structural change, and economic growth, Journal of Evolutionary Economics, 23(4), 735-766.

Romer, P. M. (1986) Increasing returns and long-run growth, The Journal of Political Economy, 94(5), 1002-1037

Solow, R. M. (1956) A contribution to the theory of economic growth, The Quarterly Journal of Economics, 70(1), 65-94.

Solow, R. M. (2007) The last 50 years in growth theory and the next 10, Oxford Review of Economic Policy, 23(1), 3-14.

Stephens, H. M., and Partridge, M. D. (2011) Do Entrepreneurs Enhance Economic Growth in Lagging Regions?, Growth and Change, 42(4), 431-465.

Swan, T. W. (1956) Economic Growth and Capital Accumulation, Economic Record, 32(2), 334-361.

Urbano, D., and Aparicio, S. (2016) Entrepreneurship capital types and economic growth: International evidence, Technological Forecasting and Social Change, 102, 34-44.

Urbano, D., Aparicio, S., and Audretsch, D. (2018) Twenty-five years of research on institutions, entrepreneurship, and economic growth: what has been learned?, Small Business Economics, in press, doi: 10.1007/s11187-018-0038-0. 